\title{
Construction of Tourism Attraction System of Yuanyang Hani's terraced fields World Heritage Area Based on SWOT Analysis
}

\author{
Wang Siqi \\ Yunnan Open University, Kunming, Yunnan, China, 650223
}

Keyword: SWOT analysis; Tourism attraction; Hani Terraces

Abstract: As a world-class tourism brand, World Heritage Area of Yuanyang Terraced Fields has its unique natural and cultural landscape. In recent years, with the development of heritage tourism, how to enhance the competitiveness of the same landscape is an important issue to be considered for the long-term attraction of the scenic spot. Through SWOT analysis of the study area, this paper constructs a tourism attraction system, aiming to provide some reference for the future development of tourism in this area.

\section{Overview of the study area}

The study area is located in the west of Yuanyang County, China. mainly across the townships of Xinjie Town, Niujiaozhai Township, Panzhihua Township and Shengcun Township. The sum of the declared core area and the buffer area totals 46,104 hectares. Including Niujiaozhai terraces, damda terraces, Duoyi terraces, tiger mouth terraces and other areas. The study area is a landscape that integrates the natural elements of terraces, mountain forest elements, Hani culture, rice culture, etc. It is the result of the interaction of nature and human beings. It has the characteristics of biodiversity, human landscape compatibility, etc. A natural template for a highly harmonious and ecologically sustainable development between humans and nature.

\section{SWOT Analysis of Tourism Development of Hani World Heritage Site}

\subsection{Advantage}

a) The study area is rich in natural resources.

b) The study area is home to seven ethnic minorities, of which the Hani are the main inhabitants.

c) Hani Terrace was successfully listed on the World Cultural Landscape Heritage List on June $22,2013$.

\subsection{Disadvantage}

a) Tourism products are single, resources need to be integrated.

b) Weak infrastructure facilities.

c) The villagers' education level is generally low, and the management of scenic spots needs to 
be improved.

d) Terraced landscapes are seasonal.

\subsection{Opportunity}

\subsubsection{Policy opportunity}

First of all, Yunnan Province is an important bridgehead for opening to the southwest. The Red River, as an important area in eastern Yunnan, is an important link between Yunnan and Vietnam. Secondly, Honghe Prefecture is connected to the two major markets of China and ASEAN, and is located at the intersection of Kunming and Hanoi in Hanoi. The location advantage is remarkable. The new pattern of tourism development in Honghe Prefecture and the layout of the "Five Zones and One Belt" of Honghe Tourism Development and "Under the background of precise poverty alleviation, it has brought many opportunities to the tourism development of Yuanyang.

\subsubsection{High-speed rail opening, traffic improvement}

At present, the Honghe high-speed railway has been opened, which has provided traffic conditions for the large number of tourists from inside and outside the province. In addition, the state has realized the traffic conditions of the internal county (city) and high-speed traffic, and realized with Kunming, Yuxi, Qujing and Wenshan. The transportation network structure of interconnection and in-link communication enables visitors to enter Honghe Prefecture with various options such as high-speed rail trains, trains, airplanes and self-driving, which provides convenience for domestic and foreign tourists and domestic and foreign tourists.

\subsubsection{Government attaches importance}

Tourism is an environmental protection industry. As a strategic pillar industry in China, tourism has also attracted the attention of all parties. In order to further develop tourism, Yunnan Province has proposed a development strategy of tourism "secondary entrepreneurship". To this end, Honghe Prefecture and Yuanyang Government It has also formulated a series of policies and measures to promote the construction of tourist towns and improve the supporting facilities for tourism, and promoted the development of tourism in the research area.

\subsubsection{Rural tourism development opportunities}

In order to further strengthen the protection of traditional villages, Yuanyang has actively carried out the work of traditional village reconstruction, and included villages such as Sakaguchi, Azko, and Dayutang in the list of traditional Chinese villages, among which, the big fish pond The village has received the support of the central government. In the first half of 2018, Yuanyang County further improved the supporting facilities for the projects of Hani Town and Azerg Village.

\section{Construction of tourism attraction system}

\subsection{Tourist attraction concept ${ }^{[5]}$}

Scholars at home and abroad have made extensive research on the meaning of tourism attraction, mainly summarized as follows:

The first is equivalent to the attractiveness of tourism resources; the second is to consider tourism attraction as the comprehensive attraction of tourism resources, tourism services and environment; the third is to divide tourism attraction into attractiveness due to rich resource 
environment and due to tourists. The attraction that drives its own needs. In this paper, the attraction of tourism resources is equated with the attraction of tourism to conduct research.

\subsection{The Connotation of the Core Attraction System of Culltural Landscape Heritage Sites}

The core attraction is the unique, extremely difficult to replicate attraction factor at the heart of many of the attraction factors in the area. ${ }^{[6]}$

Through field research, in-depth interviews, questionnaire surveys, etc., it is concluded that the study area is attracted by the unique and spectacular terraces and the unique ethnic minority culture of the Hani people. The "four-isomorphic" natural landscape system and the Hani cultural landscape of the forest-water-village are the main core attractions of this study. In addition, the scenic area planning and supporting service system can also be used as the core attraction factor of the study area. If the research area wants to stand out in a rich and diverse tourist destination, it not only needs strong natural resources, but also the cooperation of other subsystems to attract domestic and foreign tourists.

\subsection{Tourism attraction system construction}

\subsection{1. "Sillk isomorphism" natural landscape system}

The "four-isomorphic" natural landscape system is the terrace-forest-water-village system of the Hani terraced cultural heritage area in Yuanyang County. In order to maintain strong attraction in this tourist-rich area of Yunnan, the original landscape system must be intact. Sex, that is, to protect the natural landscape of the terraces, forest resources, water resources and the scenery of Hani Village.

\subsubsection{Hani Cultural Landscape System}

a) Integrate terraced cultural resources. In the study area, there are seven ethnic minorities, Han, Yi, Miao, Yi, Yao and Zhuang, which are mainly Hani people. The ethnic groups are divided into layers and merge with each other, which makes the ethnic minorities in this region outstanding. We should explore the integration of food culture, folk art, multi-ethnic culture, etc. around the Hani terraced culture, and focus on creating high-quality cultural brands in addition to the "terraced landscape".

b) Mining featured derivatives. Focusing on the landscape of Hani terraced fields, we will fully explore the derivative products and create a tourism culture product integrating catering-songshopping-shopping-tourism. Hani's distinctive food and culture products such as soybean meal, cloud green tea, terraced fish, and terraced wine, as well as Hani's special national costume products, combined with Hani's "music dance", folk songs and other song and dance culture products to create a series of boutique tourism projects. To enrich tourism products.

c) Encourage villagers to farm. The terraced landscape is different from other natural landscapes. It is the result of the interaction between humans and nature. It is a model of harmonious coexistence between man and nature. Human and natural elements are indispensable. However, with the development of society, the number of people who are willing to cultivate has become less and less. It is because terraced farming is time-consuming and labor-intensive, and the profit is meager and cannot sustain the life of the residents. In order to avoid the ridiculous terraces and no one to cultivate, a series of encouragement policies should be enacted to encourage people to continue their work. In addition, it is necessary to increase the participation of residents in the tourism industry, so that the benefits brought by tourism development benefit the villagers. 


\subsubsection{Planning and supporting service system}

a) Focusing on the development of terraced culture and characteristic service industry. Make full use of the local surplus labor force, and build a special service that integrates eating, living, traveling, playing, and purchasing on the basis of excavating Hani terrace culture, catering culture, singing and dancing culture.

b) Further strengthen infrastructure construction. Inadequate infrastructure is an important factor hindering the development of regional tourism. The infrastructure construction of tourist areas should be further strengthened, and the construction of high-grade highways and tourist reception facilities leading to scenic spots should be improved.

c) Improve the quality improvement mechanism of villagers and employees. Further improve the training mechanism for employees, provide training and learning opportunities for staff, and be certified to work. The development of the scenic spot is closely related to the local residents. It is necessary to increase publicity, organize local residents to study, improve the overall quality and understanding of residents, and enhance the participation of residents so that they can appreciate the economic benefits brought by tourism development.

d)Strengthen the planning and protection of core scenic spots. Based on the construction of landscape safety pattern, the core scenic spots in the study area include Ba Da Scenic Area, Tiger Mouth Scenic Area, Duoyi Tree Scenic Area and Niujiaozhai Scenic Area. It is a gathering area of terrace natural landscape and Hani cultural landscape, and it is also an ecologically fragile area. Construction land in the area.

Based on the graphic translation of remote sensing images in the study area, using GIS spatial analysis, this paper will divide the research into four core areas: Bada Scenic Area, Tiger Mouth Scenic Area, Duoyishu Scenic Area and Niujiaozhai Scenic Area, with a total area of 6226 hectares.

\section{Conclusion}

Based on the analysis of STOW in the study area, this paper analyzes the advantages, disadvantages, opportunities and challenges of the region, and discovers the current situation and existing problems of tourism development. Under the guidance of relevant theories, the core of Hani World Heritage Site is defined. Attractive factor. From the "four-isomorphic" natural landscape, Hani cultural landscape, scenic area planning and ancillary services, detailed research was carried out, and a tourism attraction system was constructed.

There are also some shortcomings in the research. First, the research methods need to be improved. This research is conducted through field research, in-depth interviews, questionnaires, etc., lacking quantitative evaluation. Second, due to its limitations, the tourism attraction system still needs further perfect.

\section{Acknowledgement}

Yunnan provincial department of education science research funding project

Project No.2017ZDX224

Project name: Research on tourist attraction system of heritage sites of cultural landscape based on the perspective of landscape pattern -- taking hani rice terraces as an example

\section{References}

[1] Qin Champion. The Construction of the Core Attraction System of the Commercial Street of Tourist TownTaking Zhongchagou Folk Street as an Example [D]. Master's Thesis of Chengdu University of Technology, 2013

[2] Li Yunqi. Research on the Attraction of Ethnic Tourism Destinations_-Taking Guangxi Longsheng Longji 
Terraced Fields as an Example [D]. Master's Thesis of Guilin University of Technology, 2009

[3] Chen Yanying. Research on the Attraction System and Management of Tourism Destinations [J]. Tourism Journal, 2004, (9)

[4] Huang Changcheng, Xu Nanzhen, font size. Research on the development strategy of tourism in Yuanyang County based on SWOT analysis [J]. Foreign Trade, 2013 (3).

[5] Gunn, C.A., 1988a, Vacationscape: Designing Tourist Regions New York: Van Nostrand Reinhold.

[6] Lew, Alan A.1987. A Framework of Tourist Attraction Research .Annals of Tourism Researeh. 14(4): 553-575.

[7] Zhang Kejing, Gao Kuo, Huang Chaoyang. Analysis of Attractive Factors and Municipal Research in Scenic Spots[J]. Anhui Agricultural Sciences, 2008, (34)

[8] Wang Haihong. Analysis and theoretical model of tourism attraction [J]. Science. Economy. Society, 2003, (4) 